\title{
The effect of RNA on experimentally induced memory impairment
}

CLAUDE BEAULIEU

ALLAN MEMORIAL INSTITUTE, MCGILL UNIVERSITY, MONTREAL, CANADA

The effects of RNA on retention were assessed by first exposing $S$ s to a one-trial avoidance learning situation, followed by ECS. The response measured was water consumption. The results showed that ECS seems to cause greater memory impairment in RNA-treated animals than in saline controls. Pseudo-ECS control animals showed the procedure to be an efficient measure of retention.

There is now much evidence indicating that ribonucleic acid (RNA) is intimately involved in the process of learning and of memory in general. The results obtained so far indicate that RNA has a facilitating effect on learning (Cook, 1963; Goren, 1965; Cameron et a1, 1966).

The effects of RNA on retention can be assessed by experimentally inducing memory impairment. One method which has frequently been shown to cause memory impairment is administration of an electroconvulsive shock (ECS), which seems to be one of the purest ways of disrupting retention without involving new learning.

The technique used in the present study is a modification of the one used by Cooper \& Koppenaal (1964), in which a spontaneous drinking response is inhibited by a one-trial avoidance conditioning, giving a strong electric shock contiguous to drinking. Shortly after avoidance conditioning, half the animals were subjected to an ECS, the other half being used as controls receiving an electric shock through the leg. In each of these groups, the animals had been pre-treated with RNA administered orally for several days, while the other half had never received such treatment. Two main hypotheses were made: (1) ECS-treated animals will show a smaller decrement in drinking than will pseudo-ECS animals; (2) RNA-treated animals will show more decrement in drinking than will saline controls.

\section{Method}

Subjects. Twenty-three 4-month old male hooded rats were used in this study. All animals were injected introperitoneally with their respective solution the night before experimental day, as well as a few hours after experimental treatment; the RNA animals received $160 \mathrm{mg} / \mathrm{kg}$ body weight of RNA in a $10 \%$ solution while the saline animals received an equivalent volume $(0.5 \mathrm{cc})$ of a normal saline solution.

Apparatus. The animals were tested in a Skinner box made by Foringer, Inc., which had been modified for the present purposes. The water was contained in a 10 cc pipette, the tip of which had been cut off and fitted with a standard drinking spout using a rubber fitter. The water was retained by closing the pipette with a thin rubber stopper. The avoidance UCS was an electric shock delivered through the floor of the cage. This shock was of $1 \mathrm{ma}$ intensity which lasted for $1 / 2$ sec., and was manually controlled. The convulsions were induced by administering a current of $50 \mathrm{ma}$ for $0.5 \mathrm{sec}$. via aligator clips attached to the animal's ears; for the pseudo-ECS animals, the shock was given through the hind legs.

Procedure. The Ss were water-deprived for three days before the pre-treatment session, during which they were put daily in a Skinner box for $8 \mathrm{~min}$. for purposes of adaptation. The only water they drank was in that box. On the pre- and post-treatment days, the animals were placed in the cage for $8 \mathrm{~min}$. Amount of time spent drinking was measured by continually observing the animal and recording when his mouth was in contact with the spout. Water intake was measured by directly reading the calibrated pipette. On treatment day, the animal was allowed to drink normally for $8 \mathrm{~min}$. at the end of which the electric shock was administered the first moment the animal was observed drinking. The ECS or footshock was then administered approximately 30 sec. later, in a separate room. The design of the experiment was factorial, drug being one variable, ECS being the other. The Ss were randomly assigned to these groups, all of which had six Ss, except for the pseudo-ECS; saline group which had only five.

Retention tests were conducted $24 \mathrm{hr}$. later and measurement of behavior was done as for the pre-treatment period.

Results

A three-way analysis of variance was conducted on both water consumption and time spent drinking. Analysis revealed no significant main effect as far as water consumption is concerned; however, both the period by drug and period by ECS interactions were significant $(F=23.37, \mathrm{df}=1 / 19, \mathrm{p}<.01 ; \mathrm{F}=9.05, \mathrm{df}=1 / 19, \mathrm{p}<.01$, respectively). From inspection of Fig. 1, it appears that drug interaction is mostly due to the decrease in water consumption in the saline groups in contrast with an increase in the RNA groups, while the period by ECS interaction (see Fig. 2) is due to a decrease in water consumption for the pseudo-ECS groups while the ECS groups showed an increase. Similar results were observed analyzing time spent drinking, as would be expected.

The results were also examined using suppression ratios according to the formula $S=A / A+B$ where $A$ refers to after treatment value and $B$ to before treatment value. According to this formula, no change is reflected by a value of 0.5000 . The performance of each animal using these transformed results was then submitted to two-way analyses of variance. For water 


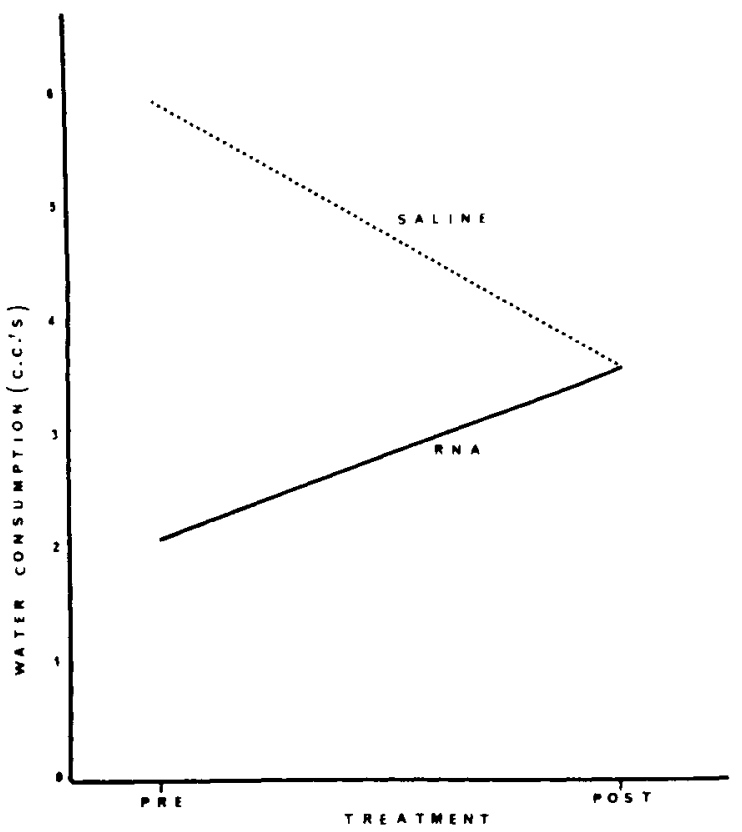

Fig. 1. Water consumption for the saline groups and RNA groups before and after experimental treatments.

level, significant drug and ECS effects were found $(F=$ 29.75, $\mathrm{df}=1 / 19, \mathrm{p}<.01 ; \mathrm{F}=20.1, \mathrm{df}=1 / 19, \mathrm{p}<.01$, respectively) as well as a significant drug by ECS interaction $(\mathrm{F}=17.57, \mathrm{df}=1 / 19, \mathrm{p}<.01)$. In order to further locate the nature of the difference, a Duncan's Range Test (summarized in Table 1) was performed on this data and it was found that the ECS-RNA groups suppressed significantly less than any of the other groups which did not differ from each other. Essentially similar results were obtained while analyzing time spent drinking, indicating that the experimental procedure caused a decrease of water consumption in all groups except for the RNA-ECS groups in which water consumption greatly increased. Thus, it seems that RNA rather than consolidating memory trace facilitates experimental amnesia due to ECS.

\section{Discussion}

The first hypothesis that ECS-treated animals would show a smaller decrement in drinking than pseudo-ECS animals has been well supported. Not only was the period by ECS interaction significant, but Fig. 1 shows an increase in water consumption in the ECS-treated group compared with a decrease in the pseudo-ECS group, both groups consuming equally at the onset. This makes it quite certain that the avoidance conditioning had an effect as witnessed in the pseudo-ECS group, and that the ECS removes the effects of this avoidance conditioning. Results dealing with the second hypothesis,

Table 1. Summary of Duncan's Range Test on the Mean Suppression Ratios for Water Level.

Pseudo-ECS: Soline ECS: Saline Pseudo-ECS: RNA ECS-RNA $\begin{array}{lll}.2724 & .3088 & .3606\end{array}$

N.B.: Means not underlined by the same straight line differ from each other at the 0.01 level of confidence.

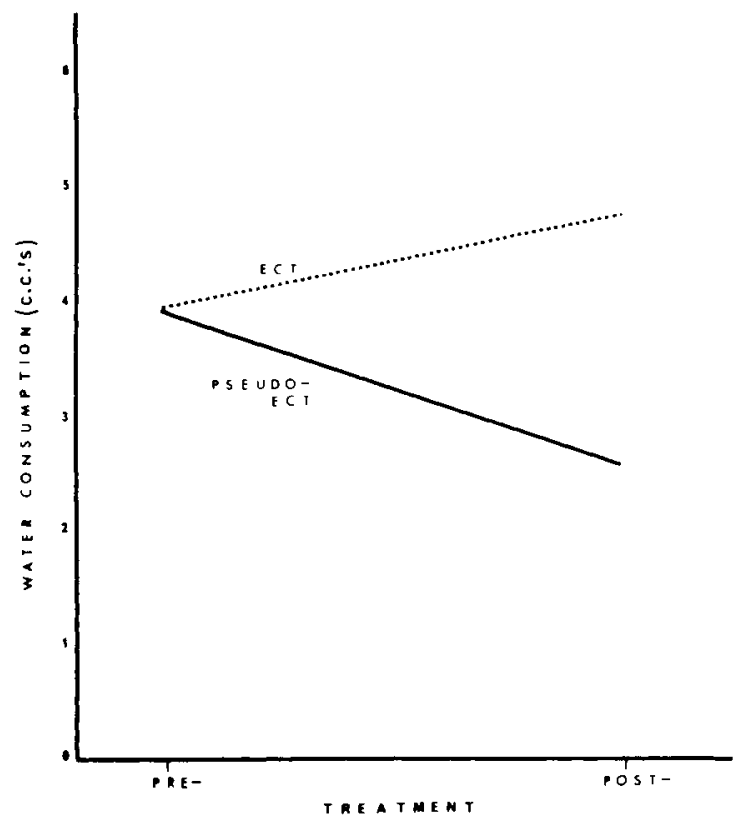

Fig. 2. Water consumption for the ECS groups and pseudo-ECS groups before and after experimental treatment.

however, are quite puzzling. Obviously RNA certainly does not increase resistance to ECS-induced amnesia. Quite the contrary. An initial observation of Fig. 2 would give rise to the suspicion that some unknown factor, possibly in the procedure, prevented the RNA-treated animals from drinking at a normal rate on the experimental day and that this unknown factor would have disappeared on the test day. However, looking at the individual groups, this hypothesis does not appear to hold: the RNA pseudo-ECS group, which does not differ in water consumption on the experimental day from the RNA-ECS animal, shows a definite reduction in water consumption from experimental to test day, while the RNA-ECS group shows a drastic increase. This is numerically illustrated in the mean suppression ratios shown in Table 1, in which the RNA-ECS animals are the only ones to show a definite increment in water consumption. Lack of change in water consumption in the RNA-ECS group could be easily accounted for in terms of complete ECS-induced amnesia; however, the increment in water level requires an additional hypothesis that ECSalone interacts with RNA to increase thirst. Research is in progress to verify this hypothesis.

\section{References}

Cameron, D. E., Kral, V. A., Solyom, L., Sved, S., Wainrib, B. Beaulieu, C., \& Enesco, H. RNA and memory. In J. Gaito (Ed.), Macromolecules and Behavior. New York: Appleton-CenturyCrofts, 1966.

Cook, L., Da vidson, A. B., Davis, D. J., Green, H., \& Fellows, E. J. Ribonucleic acid: effect on conditioned behaviour in rats Science, 1962, 141,268-269.

Cooper, R. M., \& Koppenaal, R. J. Suppression and recovery of a one-trial avoidance response after a single ECS. Psychon. Sci., $1964,1,303-304$.

Goren, Carolyn. Ribonucleic acid: influence on the maze learning ability of rats. Worm Runner's Digest, 1965, 7, 28-31. 